\title{
Optimal Inventory Policy for Stochastic Demand Using Monte Carlo Simulation and Evolutionary Algorithm
}

\author{
I Gede Agus Widyadana ${ }^{1, a}$, Alan Darmasaputra Tanudireja ${ }^{1}$, Hui-Ming Teng ${ }^{2, b}$ \\ ${ }^{1}$ Department of Industrial Engineering, Petra Christian University, Surabaya, Indonesia \\ ${ }^{2}$ Department of Business Administration, Chihlee Institute of Technology, Banciao, Taipei 22005, Taiwan, ROC \\ agede@petra.ac.id, btenghuim@mail.chihlee.edu.tw
}

\begin{abstract}
Research on inventory models has been conducted intensively, including the model for stochastic demand. However, inventory models for stochastic demand are not easy to solve using an exact algorithm. In this paper, we develop a Monte Carlo simulation method to solve inventory problems with stochastic and intermittent demand. Simulation is conducted to evaluate continuous and periodic review policies. The simulation models are optimized using the evolutionary algorithm. The models are applied to data from one bicycle shop in Indonesia for five different items. The result shows that the economic order quantity $(R, Q)$ policy is better than the $(s, S)$ policy for two items and it is better than the $(S, T)$ policy for three items.
\end{abstract}

Keywords: Inventory, Stochastic Demand, Monte Carlo Simulation, Evolutionary Algorithm.

\section{Introduction}

Continuous and periodic review inventory policies have been analyzed by many researchers and applied in many organizations. The inventory models were started with Economic Order Quantity (EOQ) by Harris in 1913. The models were developed by many researchers according to the development of industrial systems. Andriolo et al. [1] addressed 216 papers to show the evolution of the inventory models. They categorized research according to input data in three categories, which are deterministic models, stochastic models and fuzzy models. Andriolo et al. [1] found that only limited articles were related to uncertain parameters. One reason of these limited articles is the complexity of algebraic operations among random parameters with a probability distribution. However, the stochastic approach is more realistic to deal with real industry problems. Inderfurth and Vogelgesang [2] presented a simple approach for calculating dynamic safety stocks for manufacturer's stochastic production/inventory problems. An exact optimal solution for a periodic-review inventory model with multiple retailers and stochastic demand was developed by Wang [3]. Bean, Joubert, and Luhandjula [4] compared $(R, Q),(s, S)$ and a hybrid inventory policy in environments characterized by uncertainty resulting from extreme points. They showed that the hybrid policy is more reliable in an extreme scenario. The applications of EOQ for stochastic demands are important in practice. Chuang and Chiang [5] investigated the EOQ model that was applied for stochastic demands in General Motors' dealerships. Chen, Li and Jin [6] applied EOQ in agri-products for stochastic demands. They used a system dynamic simulation model to find the optimal lot size and replenishment interval.

Many researchers employed simulation methods to handle complexity of stochastic inventory problems. Kochel and Nielander [7] used combination of simulation and an optimization tool to investigate a multi location inventory model. They used simulation since analytical models have difficulty to handle various restrictive assumptions. Diaz, Bailey, and Kumar [8] solved a stochastic inventory model using simulation based optimization. The simulation based optimization combined simulated annealing, pattern search and ranking selection methods. A single simulation run of inventory process to set a target level required for a given service level was developed by Betts [9]. He concluded that the new model is easy to use by inventory managers in practice since the model does not require user modeling of functional form or parameters of the demand distributions. Do Rego and De Mesquita [10] used a simulation model to analyze the best combination of difference alternatives to record demand data, demand forecasting models and demand distribution during lead times. An $(s, S)$ inventory policy with stochastic demand and lead time was developed and solved by Ekren and Ornek [11] using simulation. They concluded that they obtained good results within reasonable computation times to solve a complex problem by using simulation.

In this paper, the simulation model is optimized using an evolutionary algorithm. Arabzad, Ghorbani, and TavakkoliMoghaddam [12] concluded that an evolutionary algorithm is capable to solve location-inventory problems by considering multi-objective, different transportation modes and third-party logistics providers. An evolutionary algorithm method was used to solve an inventory problem and the solutions were effective. Sadeghi and Niaki [13] used an evolutionary algorithm to solve a supply chain model with single vendor and multiple retailers, and the demand is fuzzy. The literatures above show that the evolutionary algorithm is good to solve some inventory problems.

In practice, stochastic and intermittent demand is found in many businesses, especially in retail. So, in this paper we try to solve inventory problems in real environment where demand is stochastic and intermittent. Customer demand usually cannot be predicted, random and not everyday occurred. This demand structure is not easy to solve analytically so we use simulation to solve the problem. 
Since demand is assumed independent each day, a Monte Carlo simulation can be used. An evolutionary algorithm is combined with the simulation to get an optimal solution. The evolutionary algorithm method is applied to data from one bicycle store to find the best variable for some policies. In this paper, we use a continuous review policy, which is economic order quantity $(R, Q)$, and some periodic review policies $(s, S$ and $S, T)$.

\section{Research Methods}

The inventory simulation model using Monte Carlo in this research uses day by day calculation, where inventory level in period $t$ can be formulate as:

$I_{t}=I_{t-1}+Q_{t}-D_{t}$

Where:

$I_{t}=$ inventory at the end of period $t$

$Q_{t}=$ order quantity arriving at period $t$

$D_{t}=$ demand at period $t$

In this paper, continuous review policies and periodic review policies are simulated to solve an inventory problem with stochastic demand in a bicycle store and to find the policy that is suitable to solve the problem. In continuous review policies, fixed order quantity $(Q)$ of an item is ordered when the stock reach the reorder point $(R)$. The policy can be illustrated in Figure 1. A company which uses this policy should review its stock continuously and it takes time to do this review process every day. Periodic review policies are different from continuous review policies. In this policy, stock is reviewed in a specific period such as weekly or monthly, and an order is set when the stock reaches a specific quantity. Figure 2 shows a periodic review policy with lead time $(L)$ and review time $(T)$. In a deterministic and constant demand, continuous review policies have better inventory cost than periodic review policies do but they need bigger effort.

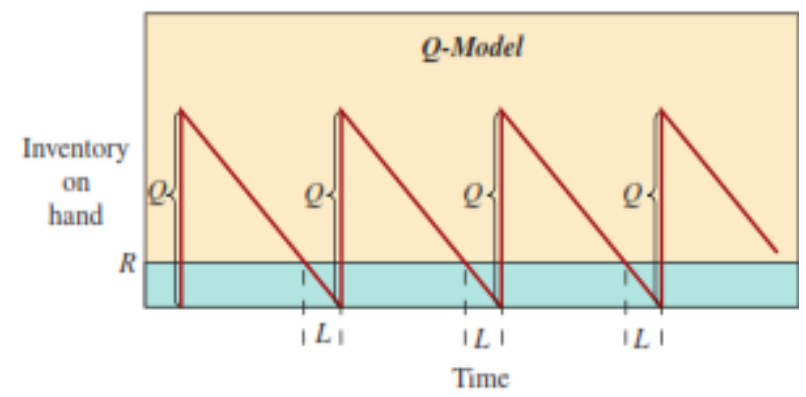

Figure 1. Continuous review Policy [14]

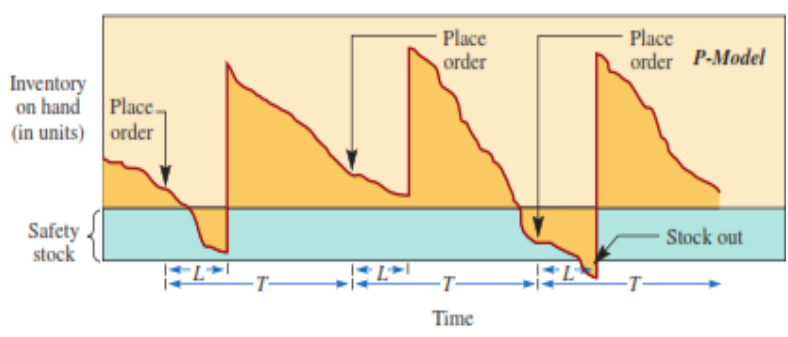

Figure 2. Periodic review Policy [14]
In this paper, three continuous review policies, which are economic order quantity, base stock level and two bin, are discussed. The first policy in continuous review policy is $(Q, R)$. In this policy, quantity $Q$ is ordered when the stock level reaches $R$ value. Value of $Q$ and $R$ can be derived using equations (2) and (3):

$Q=\sqrt{\frac{2 A D}{h}}$

$R=D+s=D+z \sigma$

Where:

$Q=$ order quantity

$A=$ setup cost

$D=$ demand rate

$h=$ holding cost per unit per period

$s \quad=$ safety stock

$z \quad=$ service level

$\sigma=$ standar deviation

The second continuous review policy is a base stock level. In this policy, an item will be ordered immediately when the stock level below the base stock value. Ordering quantity is equal to the base stock level minus the stock level in that period. The third policy is the two bin policy. In this policy, an item will be ordered if the first bin is empty. The concept of two bin policy is the same as the $(Q, R)$ policy.

For the periodic review policy, $(S, T)$ and $(s, S)$ policies are evaluated in this paper. The periodic review period base $(T)$ is derived from:

$T=\sqrt{\frac{2 A}{h \bar{D}}}$

In the $(S, T)$ policy, every $T$ period the order quantity is equal to the maximum stock level $(S)$ minus the stock level in that period. The last policy that is evaluated in this paper is $(s, S)$ policy. In this policy, inventory is evaluated every $T$ period, where $T$ is derived from equation (4). However, different from the $(S, T)$ policy, every $T$ period the item will be ordered only when the stock level below the $s$ value. The order quantity is equal with $S$ minus the stock level at that period.

The model is started from real condition where demand is collected for 18 months. Demand is modeled using a specific probability. The example of Monte Carlo simulation can be seen in Figure 3. Monte Carlo simulation is used since the demand is not constant so traditional analytic methods cannot be used. An evolutionary algorithm at Excel is used to find the optimal solution.

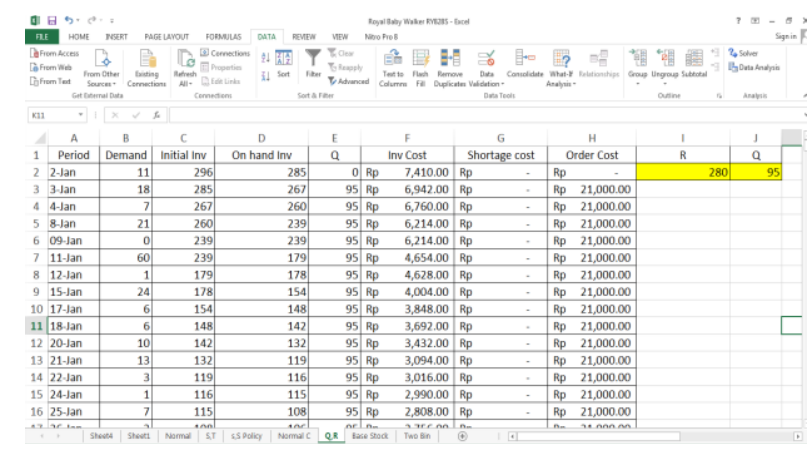

Figure 3. Monte Carlo simulation in Excel 
In Figure 3, column A is the simulated date, and column $\mathrm{B}$ is daily demand that is generated randomly using a specific probability such as described in Table 2. Columns $\mathrm{C}$ and $\mathrm{D}$ show calculation of inventory in the beginning and at the end of a day. The on hand inventory is equal with initial inventory minus demand plus $Q$ in the same period as described in equation 1 . Column $\mathrm{E}$ shows ordering quantity that is the same as EOQ for $(R, Q)$ policy. If inventory level at the end of a day reach $R$ units or below, then $Q$ units of an item will be ordered. The values of $R$ and $\mathrm{Q}$ are derived from equations 2 and 3. Columns F, G and $\mathrm{H}$ are used to calculate inventory, shortage and ordering costs. Inventory cost is equal with on hand inventory times inventory cost per unit, shortage cost is equal with shortage quantity times shortage cost per unit, and order cost is equal with ordering cost when the store orders $Q$ products and zero if not. The simulation model is solved using an Evolutionary Algorithm to get the optimal values of $R$ dan $Q$ as shown in Figure 4 . An evolutionary algorithm is used to solve the problem since this metaheuristic method can find near optimal solution and this algorithm is provided by Excel. The only constraints are minimum and maximum values of $R$ and $Q$. The minimum values of $R$ and $Q$ are zero and the maximum values are set big enough so the optimal decision variables of $R$ and $Q$ are not the same as the maximum values. The simulation is run up to five years and replicated five times.

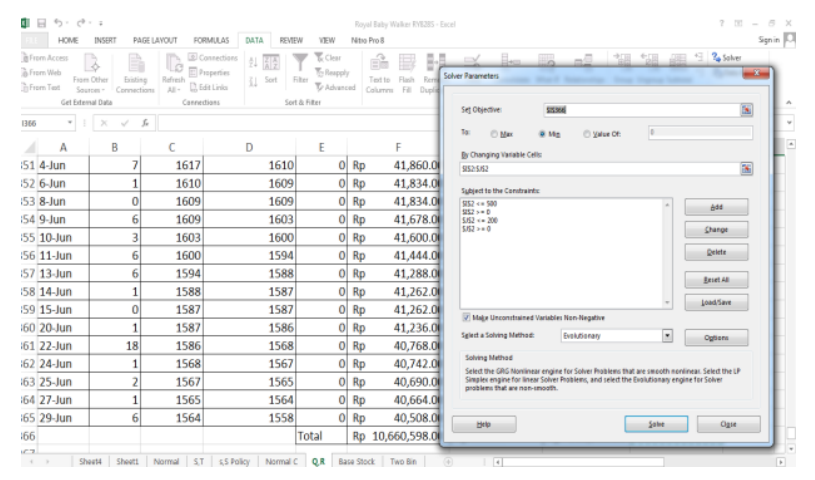

Figure 4. Evolutionary Algorithm solution using Excel

\section{Result and Discussion}

The inventory policies were evaluated using data from a bicycle store. Five bicycle products were used, where all of them are the most favorite products in that store. Daily demand data was collected from January 1, 2014 until June 30, 2015. The ordering lead times varied from 2 to 3 weeks. The inventory holding cost, shortage cost and initial on hand inventory are shown in Table 1 . The ordering cost is equal to Rp. 21,000 .

Tabel 1. Inventory holding cost, shortage cost, and initial on hand inventory

\begin{tabular}{|c|c|c|c|}
\hline Product & $\begin{array}{c}\text { Inventory } \\
\text { Holding Cost (rupiah) }\end{array}$ & $\begin{array}{l}\text { Shortage Cost } \\
\text { (rupiah) }\end{array}$ & $\begin{array}{l}\text { On hand Inven- } \\
\text { tory (units) }\end{array}$ \\
\hline RY828S & 3,865 & 50,000 & 209 \\
\hline RY838 & 4,348 & 45,000 & 72 \\
\hline RY9682CJ & 9,180 & 65,000 & 88 \\
\hline $16 \mathrm{FIB}$ & 19,487 & 80,000 & 131 \\
\hline $18 \mathrm{FIB}$ & 21,742 & 90,000 & 0 \\
\hline
\end{tabular}

Table 2. Data probability for $16 \mathrm{FIB}$ product

\begin{tabular}{cccc}
\hline Daily demand & Occurrence & Probability & Cumulative \\
\hline 0 & 256 & 0.46886 & 0.46886 \\
1 & 144 & 0.26373 & 0.73260 \\
2 & 51 & 0.09341 & 0.82601 \\
3 & 42 & 0.07692 & 0.90293 \\
4 & 21 & 0.03846 & 0.94139 \\
5 & 14 & 0.02564 & 0.96703 \\
6 & 4 & 0.00733 & 0.97436 \\
7 & 4 & 0.00733 & 0.98168 \\
8 & 1 & 0.00183 & 0.98352 \\
9 & 1 & 0.00183 & 0.98535 \\
10 & 3 & 0.00549 & 0.99084 \\
11 & 4 & 0.00733 & 0.99817 \\
16 & 1 & 0.00183 & 1 \\
\hline
\end{tabular}

Simulation was conducted day by day for five years and five replications were used. Demand data was used to set demand probability for each day. Demand probability was used to generate data for the next five years. The example of data probability for 16FIB product is shown in Table 2.

The optimal values of $s$ and $S$ were derived using the Evolutionary Algorithm, where the base value of $T$ was derived using equation 4 . The evolutionary algorithm was used since the model is a nonlinear model. The optimal values of $s$ and $S$ for every item can be seen in Table 3 .

Tabel 3. The optimal values of $s$ and $S$

\begin{tabular}{lcc}
\hline \multicolumn{1}{c}{ Items } & S (unit) & S(unit) \\
\hline RY828S & 270 & 327 \\
RY838 & 230 & 275 \\
RY9682CJ & 115 & 142 \\
16FIB & 45 & 59 \\
18FIB & 46 & 58 \\
\hline
\end{tabular}

Since simulation method was used and demand quantity could be different in every replication, performance of each method was compared using inventory cost per unit. The total inventory cost per unit for every method for 16FIB product is shown in Table 4, where the total inventory cost per unit is total inventory cost derived from the simulation divided by total item sold.

Table 4. Total inventory cost per unit for $16 \mathrm{FIB}$ product

\begin{tabular}{lrrrrr}
\hline \multirow{2}{*}{ Policy } & \multicolumn{5}{c}{ Replication } \\
\cline { 2 - 6 } & \multicolumn{1}{c}{$\mathbf{1}$} & \multicolumn{1}{c}{$\mathbf{2}$} & \multicolumn{1}{c}{$\mathbf{3}$} & \multicolumn{1}{c}{$\mathbf{4}$} & \multicolumn{1}{c}{$\mathbf{5}$} \\
\hline$S, T$ & $11,475,600$ & $11,394,804$ & $11,439,144$ & $11,486,664$ & $11,607,792$ \\
$S, S$ & $10,277,792$ & $9,547,328$ & $9,344,088$ & $11,264,204$ & $9,778,748$ \\
$Q, R$ & $9,075,504$ & $8,862,084$ & $8,967,768$ & $9,532,248$ & $10,696,076$ \\
Base Stock & $24,658,652$ & $24,768,192$ & $25,101,768$ & $24,579,480$ & $26,220,776$ \\
Two Bin & $9,075,504$ & $8,862,084$ & $8,967,768$ & $9,532,248$ & $10,696,076$ \\
\hline
\end{tabular}

The best policy for every product using simulation is shown in Table 5. Table 5 shows that $(Q, R)$ policy is the best policy for all product. The result in this case study supports the previous research's result that continuous review policies have smaller inventory cost than periodic review policies. However the continuous review policies need more effort by checking inventory level continuously. For some products, the periodic review policies are not significantly different than the continuous review ones, except for product RY9682CJ. In some products, $(s, S)$ policy has better performance than $(S, T)$ policy but not for 
RY828S, so the store prefers to use $(s, S)$ policy than $(S, T)$ policy.

Table 5. Best policy for every product

\begin{tabular}{ll}
\hline Product & Best Policy \\
\hline RY828S & $S, T ; Q, R$ \\
RY838 & $S, T ; s, S ; Q, R$ \\
RY9682CJ & $Q, R$ \\
$16 F I B$ & $S, S ; Q, R$ \\
$18 F I B$ & $S, S ; Q, R$ \\
\hline
\end{tabular}

\section{Conclusion}

Inventory cost varies depending on the business field, however inventory cost is quite high. Due to this reason, many research focus on inventory to minimize the cost, however not many research emphasize on solving stochastic inventory problems. In this paper, we analyze performance of some inventory policies with stochastic and intermittent demand. Simulation and evolutionary algorithm were used to solve the problem since the problem is difficult to solve using an analytical solution.

Comparison of different policies was conducted using data from a bicycle store in Indonesia. Five products that have high selling frequencies were used. Demand data was collected to be used as demand prediction for the simulation. Simulation was conducted for five years and five replications.

The result shows that the performance of $(Q, R)$ policy is the best for all products, however the policy is not significantly different than $(s, S)$ policy for three products and $(S, T)$ policy in two products. The result can give recommendation for managements to use a continuous review policy to reduce their inventory cost. However, they still can use a periodic inventory policy if they cannot review their stock level daily due to the big variety of products or lack of inventory systems. This paper can be extended by including some conditions that are found in real environments such as defect products or warranty.

\section{References}

1. Andriolo, A., Battini, D., Grubbstrom, R.W., Persona, A., and Sgarbossa F., A Century of Evolution from Harris's Basic Lot Size Model: Survey and Research Agenda, International Journal of Production Economics, 155, Sep 2014, pp. 16-38.

2. Inderfurth, K. and Vogelgesang, S., Concepts for Safety Stock Determination Under Stochastic Demand and Different Types of Random Production Yield, European Journal of Operational Research, 224(2), Jan 2013, pp. 293-301.
3. Wang, Q., A Periodic-Review Inventory Control Policy for a Two-Level Supply Chain with Multiple Retailers and Stochastic Demand, European Journal of Operational Research, 230(1), Oct 2013, pp. 53-62.

4. Bean, W.L., Joubert, J.W., and Luhandjula, M.K., Inventory Management Under Uncertainty: A Military Application, Computers \& Industrial Engineering, 96, Jun 2016, pp. 96-107.

5. Chuang, C.H. and Chiang, C.Y., Dynamic and Stochastic Behavior of Coefficient of Demand Uncertainty Incorporated with EOQ Variables: An Application in Finished-Goods Inventory from General Motors' Dealerships, International Journal of Production Economics, 172, Feb 2016, pp.95-109

6. Chen, W., Li, J., and Jin, X., The Replenishment Policy of Agri-Products with Stochastic Demand in Integrated Agricultural Supply Chains, Expert Systems with Applications, 48, Apr 2016, pp. 55-66.

7. Kochel, P. and Nielander, U., Simulation-Based Optimization of Multi-Echelon Inventory Systems, International Journal of Production Economics, 93-94, 2005, pp. 505-513.

8. Diaz, R., Bailey, M.P., and Kumar, S., Analyzing a Lost-Sale Stochastic Inventory Model with MarkovModulated Demands: A Simulation-Based Optimization Study, Journal of Manufacturing Systems, 38, Jan 2016, pp. 1-12.

9. Betts, J.M., Calculating Target Inventory Levels for Constrained Production: A Fast Simulation-Based Approximation, Computers \& Operations Research, 49, Sep 2014, pp. 18-27.

10. Do Rego, J.R. and De Mesquita, M.A., Demand Forecasting and Inventory Control: A Simulation Study on Automotive Spare Parts, International Journal of Production Economics, 161, Mar 2015, pp. 1-16.

11. Ekren, B.Y. and Ornek, M.A., Determining Optimum $(\mathrm{s}, \mathrm{S})$ Levels of Floor Stock Items in a Paint Production Environment, Simulation Modeling Practice and Theory, 57, Sep 2015, 133-141.

12. Arabzad, S.M., Ghorbani, M., and Tavakkoli-Moghaddam, R., An Evolutionary Algorithm for a New Multi-Objective Location-Inventory Model in a Distribution Network with Transportation Modes and ThirdParty Logistics Providers, International Journal of Production Research, 53(4), 2015, pp. 1038-1050.

13. Sadeghi, J. and Niaki, S.T.A., Two Parameter Tuned Multi-Objective Evolutionary Algorithms for a BiObjective Vendor Managed Inventory Model with Trapezoidal Fuzzy Demand, Applied Soft Computing, 30, May 2015, pp. 567-576.

14. Jacobs, F.R and Chase, R.B., Operations and Supply Chain Management: The Core, $3^{\text {rd }}$ ed., McGrawHill/Irwin Series Operations Decision Sciences, 2013. 